\title{
Cantrell pentalojisi
}

\author{
Cantrell's pentalogy
}

Ayhan Atıgan, Ümit Çabuş

Gönderilme tarihi:22.11.2018

Kabul tarihi:08.02.2019

Özet

Cantrell pentalojisi oldukça nadir görülen ve orta hat supraumbilikal abdominal defekt, sternum alt uç defekti, diafragma ön kısmında defekt, perikardın diafragma yüzünün eksikliği ve intrakardiak anomaliler ile karakterize bir sendromdur. Az görülen bir anomaliler grubu olması nedeniyle ilgili literatür gözden geçirilerek olgumuza ait özellikler sunulmuştur.

Anahtar Kelimeler: Cantrell pentalojisi, abdominal duvar defekti (omfalosel), ektopia kordis.

Atıgan A, Çabuş Ü. Cantrell pentalojisi. Pam Tıp Derg 2019;12:337-341.

\begin{abstract}
Pentalogy of Cantrell is a rare congenital malformation. It's composed of defects of lower sternum, anterior diaphgram, midline supraumbilical abdominal wall, diaphragmatic pericardium with ectopia cordis. In this article we discussed Cantrell's pentalogy with the literature findings.
\end{abstract}

Key Words: Cantrell's pentalogy, abdominal wall defects (omphalocele), ectopia cordis.

Atıgan A, Çabuş Ü. Cantrell's pentalogy. Pam Med J 2019;12:337-341.

\section{Giriş}

Cantrell pentalojisi, ilk olarak 1958 yılında Cantrell, Haller ve Ravitch tarafından 5 vakalık bir seride tanımlanan karın duvarı, sternum, diafram, perikard ve kalp defektlerini içeren bir sendromdur [1]. Cantrell-Haller-Ravitch Sendromu, pentaloji sendromu, peritoneoperikardial diafram hernisi ve torako-abdominal ektopia kordis isimleriyle de anılan Cantrell pentalojisi 1/65.000-1/200.000 doğumda görülen nadir bir sendromdur. Erkek/kız oranı 1/1'dir [2].

Sendroma özgü olan anomalilerde farklılıklar olabildiği gibi, bazı olgularda beş grup anomali dışında cantrell pentalojisine eşlik eden değişik anomaliler de literatürde bildirilmiştir [3, 4]. Ensefalosel, meningomiyelosel, anensefali, spina bifida ve kraniyorafliflizis gibi nöral tüp defektleri Cantrell pentalojisi ile birlikte görülebilmektedir $[5,6]$. Konsepsiyonun 1418. günlerinde intraembriyonik mezodermin ventromedial migrasyonunda yetersizlik patogenezde rol oynamaktadır [7]. Özellikle gestasyonun 14-15. günlerinde paryetal ve splenik mezodermin diferansiasyonunda patoloji olduğu düşünülmektedir. Paryetal mezodermdeki problemler diyafram ve abdominal defektlere, splanknik mezodermdeki ise kalp ve perikardda defektlere neden olur [8].

$\mathrm{Bu}$ olguda düzenli takip olmayan ve ikinci trimesterin sonunda Cantrell pentalojisi tanısı konan ve aile tarafından sonlandırma istenmeyen ikiz gebelikte Cantrell sendromunun literatür eşliğinde tartışılması amaçlanmıştır.

\section{Olgu sunumu}

Son adet tarihi 19/05/2017 olan 29 yaşındaki hastamız 21 hafta 4 gün ikiz gebelik ve fetal anomali şüphesi ile kliniğimize sevk edildi. Özgeçmişinde özellik olmayan hastamızda ve ailesinde konjenital anomali öyküsü bulunmuyordu. İkiz gebeliği mevcut olan hastamızın geçirilmiş operasyon ve gebelik öyküsü de yoktu. Kadın Hastalıkları ve Doğum Anabilim Dalı ve Radyoloji Anabilim Dalı'nda ayrı ayrı yapılan obstetrik ultrasonografi

Ayhan Atıgan, Arş Gör. Dr. Pamukkale Üniversitesi Tıp Fakültesi, Kadın Hastalıkları ve Doğum Kliniği, DENiZLli, e-posta: dratigan@hotmail.com (orcid.org/0000-0002-7257-0593) (Sorumlu yazar)

Ümit Çabuş, Dr. Öğretim Üyesi, Pamukkale Üniversitesi Tıp Fakültesi, Kadın Hastalıkları ve Doğum Kliniği, DENiZLi, e-posta: tus20tus@hotmail. com (orcid.org/0000-0001-5478-5673) 
incelemelerinde dikoryonik diamniyotik 21 hafta 6 günlük ve 20 hafta 6 günlük intrauterin ikiz canlı gebelik saptandı. Oligohidramniyoz olan fetusta fetal karın ön duvarında geniş bir defektin bulunduğu, karaciğer, mide ve kalbin büyük bir kısmının bu defekt düzeyinde ekstrakorporal yerleşimli olduğu, defektin zarla çevrili olup umblikal kordun bu kese içinde olduğu, hidrosefali izlendi (Resim 1a, 1b ve 1c). Hastada fetal omfalosel ve ektopia kordis bulguları ile Cantrell pentalojisi düşünüldü. Hastamıza Perinatoloji polikliniğimizde fetosit önerildi. Hastamı gebelik devamını istedi. Başka şehirde ikamet eden hastamız kontrollerine gelmedi. Hasta gebeliğinin 32 hafta ve 4. gününde (02/01/2018) yeniden kuvvetli sancıları ile polikliniğimize başvurdu. Daha önceden de Cantrell pentalojisi olarak tanımlanan fetusta kardiyak aktivite izlenmedi ve ex fetus olarak kabul edildi. Canlı fetusun transvers duruşu nedeniyle kuvvetli kasılmaları olan gebemiz C/S ile doğumunu yaptı. Canlı fetus 1860 gr kız iken, iuex olan fetus 1430 gr erkek görünümlüydü. Doğumda patolojiye gönderilen plasentalardan canlı fetusun kordonunda 2 arter 1 ven görülürken, ex fetusun kordonunda yalnızca 2 arter içerdiği raporlanmıştır.

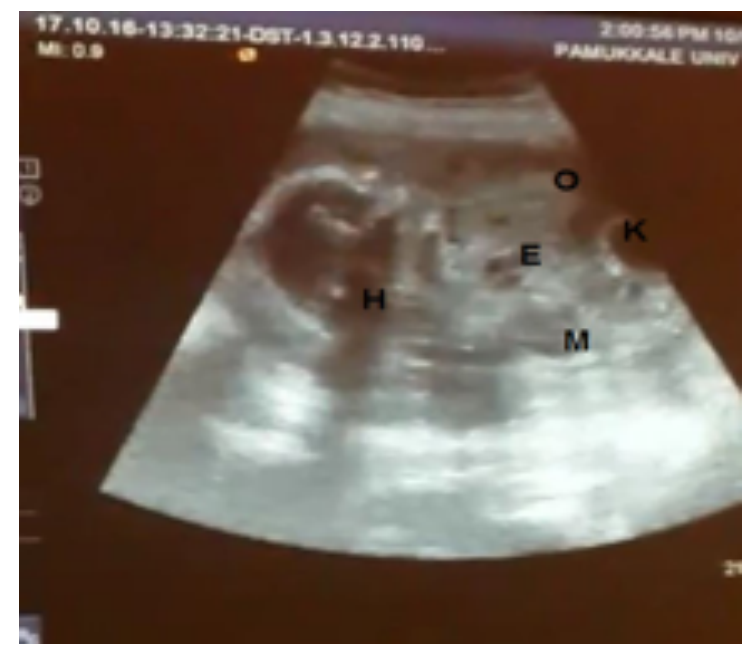

Resim 1a. O: Omfalosel kesesi, H: Hidrosefali, E: Ektopia kordis ve anormal kalp yapısı, K: Anaekoik kistik yapı, M: Meningomyelosel.

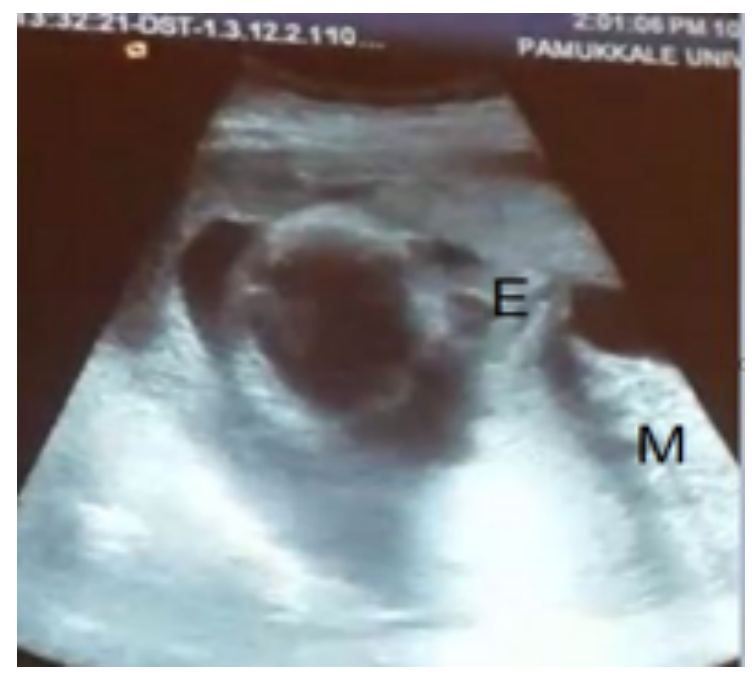

Resim1b.E:Ektopiakordis, M:Meningomyelosel kesesi.

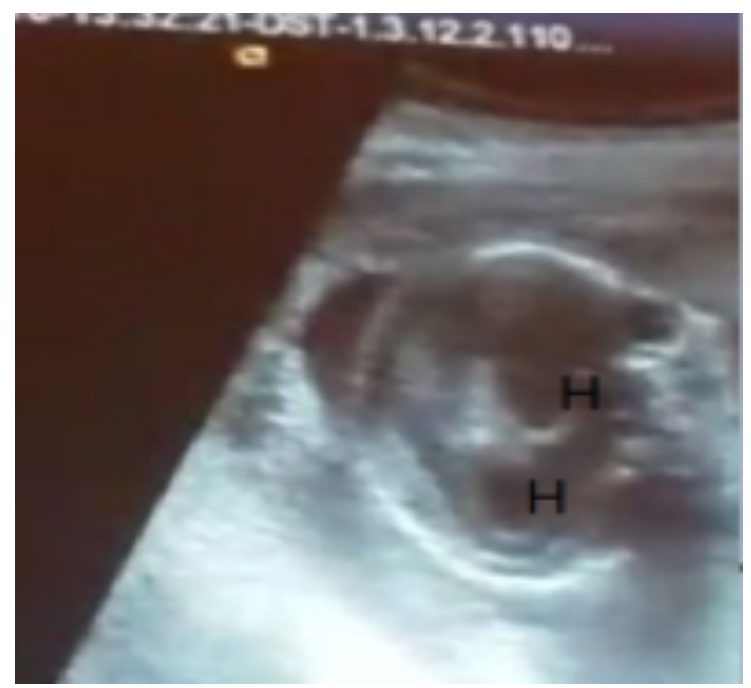

Resim 1c. H: Hidrosefali.

Ex fetusun yapılan makroskopik incelemesinde toraks ve batın ön duvarının tamamen açık olduğu ve bu defektten iç organların protrüze olduğu gözlenmiştir (Resim $2 a, 2 b$ ve $2 c$ ). Ayrıca vertebral füzyon bozukluğu dikkat çekmiştir. Otopsisi ailesi tarafından reddedilen ex fetusa kromozom incelemesi yapılamadı. Takiplerinde komplikasyon gelişmeyen hasta postoperatif 2. günde taburcu edildi. 


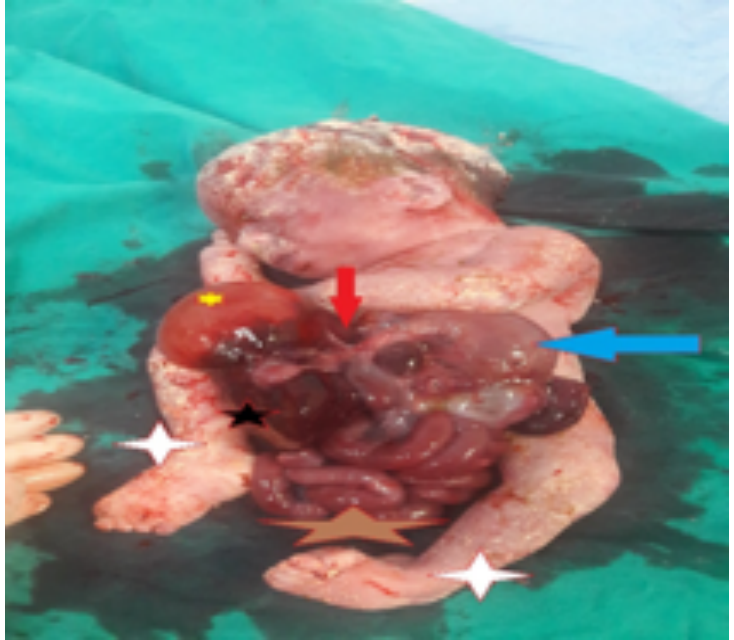

Resim 2a. Kırmızı ok ektopi kordis, mazi ok mide, beyaz yıldız pes ekinovarus.

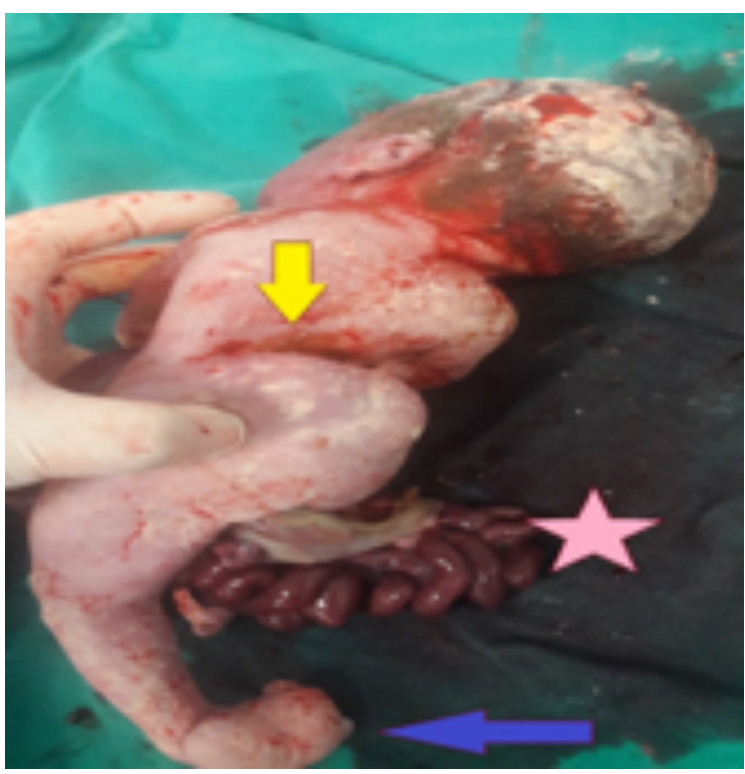

Resim 2b. Sarı ok skolyoz (vertebra anomalisi), Pembe yıldız karaciğer, mor ok pes ekinovarus.

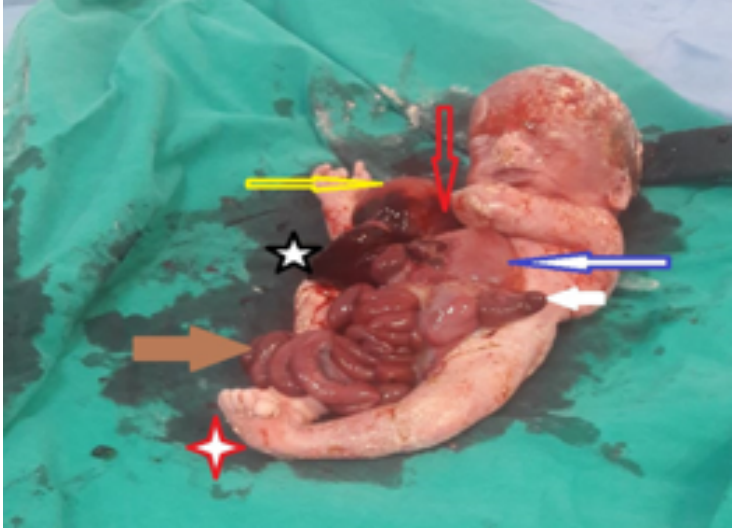

Resim 2c. Kırmızı ok ektopi kordis, beyaz ok dalak, kahverengi ok barsaklar, beyaz yıldız pes ekinovarus, sarı ok kistik yapı, siyah yıldız karaciğer.

\section{Tartışma}

Epigastrik omfalosel,sternum alt uç defekti, diafragma hernisi, perikardın diafragma yüzünün eksikliği ve kardiak anomalilerden oluşan Cantrell pentalojisinin tanısını koymak için en az üç komponentinin olması yeterlidir [9]. Literatürde 1987-2007 arasında 20 yıllık sürede toplam 58 vaka bildirilmiştir [10]. Cantrell pentalojisi, Toyama ver ark. tarafından 1972 yılında 3 gruba ayrılmıştır. Birinci grupta tüm defektler yer alır. İkinci grupta sadece 4 defektin görülmesi mevcutken, Üçüncü grupta ise defektlerin çeşitli kombinasyonları ile inkomplet olarak görülmesi yer alır [9]. Olgumuz tüm komponentlerin izlenmesi nedeniyle Toyama sınıflamasına göre birinci grupta yer almaktadır.

Omfalosel bu sendromun anomali kompleksi içerisindeki temel bileşendir. Embriyonik yaşamın 3. haftasından itibaren mezoderm migrasyonunun sefalik ve kaudal kısmında yetersizliği omfaloselin patogenezindeki temel mekanizmadır. Füzyon yetersizliği sefalik kısımda olursa dudak ve damak yarıkları, sternum defektleri ve omfalosel gelişir [11]. Abdomendeki defektlerin gelişmesi ise farklı bir mekanizma sonucunda mezodermin ventral migrasyonu yetersizliği nedeniyle oluşur. Bu tür olgular genellikle sporadiktir ve çoğu $X$ kromozomunun lokal genlerindeki mutasyonlarından dolayı geliştiği düşünülmektedir [12]. Bizim olgumuzun ailesel hikayesi bulunmamakla birlikte sporadiktir. Postpartum dönemde ailesi tarafından karyotip 
analizine izin verilmediğinden, ex fetusun kromozom yapısı tespit edilememiştir.

Cantrell pentalojisinde prognozu belirleyen en önemli etken kalp anomalileridir. Ventriküler septal defekt (VSD), atrial septal defekt (ASD), büyük damarların transpozisyonu, pulmoner arter hipoplazisi gibi anomaliler daha sık görülen kardiak patolojilerdir [13]. Kendi olgumuzda torako-abdominal tip ektopia kordis saptanmıştır. Ön duvar defektinin büyük olması fetusun yaşam intimalini azaltır. Bizim olgumuz intrauterin mort fetus olarak tespit edilmiştir.

Cantrell pentalojisi tanımlandığı ilk günden itibaren beş ana defektten başka olgularda ek patolojiler de tanımlanmıştır [14]. En çok yarık damak ve dudak, vertebral anomaliler, pulmoner hipoplazi, ensefalosel ve club foot anomalileri bildirilmiştir [15, 16]. Bizim olgumuzda pes ekinavarus,ektopi kordis, meningomyelosel, akciğer hipoplazisi, omfalosel, kifoskolyoz, hidrosefali gözlenmiştir. Ayrıca ikiz gebelikte fetusun biri sağlıklı olup birininde cantrell sendromuna sahip olduğu dünya genelinde çok nadir vaka vardır. Üstelik meningomyelosel, hidrosefali ve pes ekinavarus gibi ek anomalilerin görülmesiyle vakamız daha da ilginçleşmiştir.

Prenatal dönemde Cantrell sendromu tanısı USG veya magnetik rezonans (MR) ile çok rahat konulabilmektedir. Özellikle son yıllarda teknolojinin gelişmesiyle birlikte bu sendrom ilk trimesterde de rahatça tespit edilebilmektedir. Birinci trimester taramasında artmış ense kalınlığı ve kistik higroma akla Cantrell sendromunu getirmelidir. Bizim olgumuz takipsiz olduğundan birinci trimester taraması yapılamamıştır. USG'de omfalosel tespit edilmesi durumunda Cantrell pentalojisinden şüphelenilmelidir. Ektopia kordisin gösterilmesi tanı için kritiktir. Omfalosel ile birlikte ektopia kordis genellikle torako-abdominal ön duvardan birlikte protrüze olmaktadır [17].

Prenatal dönemde Cantrell pentalojisi tespit edilen olgular için aileye ayrıntılı bilgi verilmelidir. Gebeliğin devamına karar verilen olgularda doğum öncesinde pediatrik cerrah hazırda tutulmalıdır.

Sonuç olarak fetusta omfalosel tespit edilmesi durumunda ultrasonografik muayuene ayrntılı yapılmalıdır ve akla Cantrell pentalojisi getirilmelidir. Cantrell pentalojisi tanısı konan olgular tersiyer merkezde perinatolog, çocuk kardiyolojisi, genetik danışmanlıkla takip edilmelidir.

Çıkar İlişkisi: Yazarlar çıkar ilişkisi olmadığını beyan eder.

\section{Kaynaklar}

1. Cantrell JR, Haller JA, Ravitch MM. A syndrome of congenital defects involving the abdominal wall, sternum, diaphragm, pericardium, and heart. Surg Gynecol Obstet 1958;107:602-614.

2. Desselle C, Herve P, Toutain A, Lardy H, Sembely C, Perrotin F. Pentalogy of Cantrell: Sonographic assessment. J Clin Ultrasound 2007;35:216-220. https://doi.org/10.1002/jcu.20318

3. Carmi R, Boughmann JA. Pentalogy of Cantrell and associated midline anomalies: A possible ventral midline developmental field. Am J Med Genet 1992;42:90-95. https://doi.org/10.1002/ajmg.1320420118

4. Bognoni V, Quartuccio A. First trimester sonographic diagnosis of Cantrell's pentalogy with exencephaly. J Clin Ultrasound: JCU 1999;27:276-278.

5. Dane C, Dane B, Yayla M, Cetin A. Prenatal diagnosis of a case of pentalogy of Cantrell with spina bifida. J Postgrad Med 2007;53:146-148.

6. Ranganath P, Pradhan M. Complete pentalogy of Cantrell with craniorachischisis: A case report. J Prenat Med 2012;6:10-12.

7. Cantrell JR, Haller JA, Ravitch MM. A syndrome of congenital defects involving the abdominal wall, sternum, diaphragm, pericardium and heart. Surg Gynecol Obstet 1958;107:602-614.

8. Ghidini A, Sirtori M, Romero R, Hobbins JC. Prenatal diagnosis of pentalogy of Cantrell. J Ultrasound Med 1988;7:567-572.

9. Toyama WM. Combined congenital defects of anterior abdominal wall, sternum, diafragm, pericardium and heart: A case report and review of the syndrome. Pediatrics 1972;50:778-792.

10. Van Hoorn JH, Moonen RM, Huysentruyt CJ, van Heurn LW, Offermans JP, Mulder AL. Pentalogy of cantrell: Two patient and a review to determine prognostic factors for optimal approach. Eur J Pediatr 2008;167:29-35. https://doi.org/10.1007/s00431-007-0578-9

11. Kachare MB, Patki VK, Saboo SS, Saboo SH, Ahlawat K. Pentalogy of Cantrell associated with exencephaly and spinal dysraphism: Antenatal ultrasonographic diagnosis. Case report. Med Ultrason 2013;15:237239.

12. Parvari R, Carmi R, Weissenbach J, Pilia G, Mumm $S$, Weinstein $Y$. Refined genetic mapping of X-linked thoracoabdominal syndrome. Am J Med Gen 1996;61:401-402. https://doi.org/10.1002/(SICl)10968628(19960202)61:4<401::AID-AJMG18>3.0.CO;2-W 
13. Yang TY, Tsai PY, Cheng YC, Chang FM, Chang $\mathrm{CH}$. Prenatal diagnosis of pentalogy of Cantrell using three-dimensional ultrasound. Taiwan $\mathrm{J}$ Obstet Gynecol 2013;52:131-132. https://doi.org/10.1016/j. tjog.2013.01.017

14. Fernandez MS, Lopez A, Vila JJ, Lluna J, Miranda J. Cantrell's pentalogy. Report of four cases and their management. Pediatr Surg Int 1997;12:428-431.

15. Bognoni V, Quartuccio A. First-trimester sonographic diagnosis of Cantrell's pentalogy with exencephaly. J Clin Ultrasound 1999;27:276-278.

16. van Hoorn $\mathrm{JH}$, Moonen RM, Huysentruyt $\mathrm{CJ}$, van Heurn LW, Offermans JP, Mulder AL. Pentalogy of Cantrell: Two patients and a review to determine prognostic factors for optimal approach. Eur J Pediatr 2008;167:29-35. https://doi.org/10.1007/s00431-0070578-9

17. Doganay S, Kantarci M, Tanriverdi EC. Pentalogy of cantrell with craniorachischisis: MRI and ultrasonography findings. Ultraschall Med 2008;5:278280. https://doi.org/10.1055/s-2008-1027996 